\title{
Cast Iron: A Historical and Green Material Worthy of Continuous Research
}

\author{
Jacques Lacaze ${ }^{1 *}$, Steve Dawson ${ }^{2}$, Alain Hazotte ${ }^{3}$ \\ ${ }^{1}$ CIRIMAT, Université de Toulouse, 31030 Toulouse, France \\ ${ }^{2}$ SinterCast AB, Kungsgatan 2, 64130 Katrineholm, Sweden \\ ${ }^{3}$ LEM3, Université de Lorraine, Arts \& Metiers Paris Tech, CNRS, 7 rue Félix Savart, 57070 Metz, France
}

\begin{abstract}
Throughout history, cast iron has been unique amongst metallic materials. No other metal can boast such a long history, together with such a wide diversity of variants, properties, and applications. Arguably, no other material can claim to have such complexity. While the cast iron foundry produces myriad components, researchers and engineers have humbly ensured the continued development of this sophisticated material. We control this process not with furnaces and wirefeeders, but with knowledge. This knowledge enables the creation of a material with a unique combination of design flexibility, mechanical properties, wear resistance, recyclability, low life cycle energy consumption, and low cost. And it will be with the continued pursuit of understanding and knowledge that tomorrow's researchers and engineers will ensure the continued growth of new material variants, with improved material properties and new applications that make the world a better place. Cast iron: thousands of years of development and progress behind us; thousands of fascinating mysteries and opportunities ahead of us.
\end{abstract}

Keywords: Cast iron; History; Market share

\section{Introduction}

Cast iron is an easy-to-shape material whose properties have evolved over the years in line with improvements in the technical and scientific fields. As of 2018, the various forms of cast iron represented $70 \%$ of the 110 million tons of total metal cast per year worldwide (10\% for cast steel, $20 \%$ for aluminum and other alloys) (Census of Word Casting Production, 2019). Cast iron is a low-cost recyclable material with relatively low levels of pollution when compared to its present-day competitors. This is schematically illustrated in Figure 1, where so-called gray cast iron is compared with cast steels and aluminum alloys, in terms of price per MPa of yield strength vs. embodied energy (Figure $1 \mathrm{a}$ ), and $\mathrm{CO}_{2}$ footprint (Figure 1b). The latter two terms refer to energy used and $\mathrm{CO}_{2}$ emitted, respectively, for the primary production, casting, and recycling of $1 \mathrm{~kg}$ of alloy.

Long before the dollar was established as a universal term of reference, and before aluminum had even been thought of, cast iron was already attractive for use in several applications in agriculture, domestic applications, and decoration. Cast iron is, in fact, a historic material that first appeared during the Iron Age, when the temperatures in furnaces became high enough for the processing of iron ore. It is therefore of first interest to summarize the evolution of cast iron materials, since its first inception up to the 
modern era, which we will do in the section to follow. As with other materials, over the last two centuries, several significant steps have been taken in the processing of cast iron, in casting technology, and in the cast iron itself. These are covered in the following sections.

Nowadays, cast iron consists of a family of materials, as depicted in Figure 2. Two main branches can be defined depending on the carbon-rich phase, which can be either cementite and other carbides, or graphite. Alloys within this former branch, also called white cast iron due to the color of their rupture surface, have high wear properties and good heat and corrosion resistance when alloyed but tend to be brittle. This branch, however, is a minor part of the cast iron family and most of the current production consists of gray (or graphitic) cast irons, in which the carbon-rich phase is graphite, giving a dark coloring to the rupture surfaces. The vast majority of these irons are based on Fe-C-Si alloys, and thus, can also be called silicon cast iron. This group of irons will be the focus of this paper. Ni-resist graphitic cast irons are heat and corrosion resistant, while very high-Si alloys are corrosion resistant. Behind the sorting in Figure 2 is a continuous evolution of cast iron alloys and their processing, as described in the section "Main Steps".
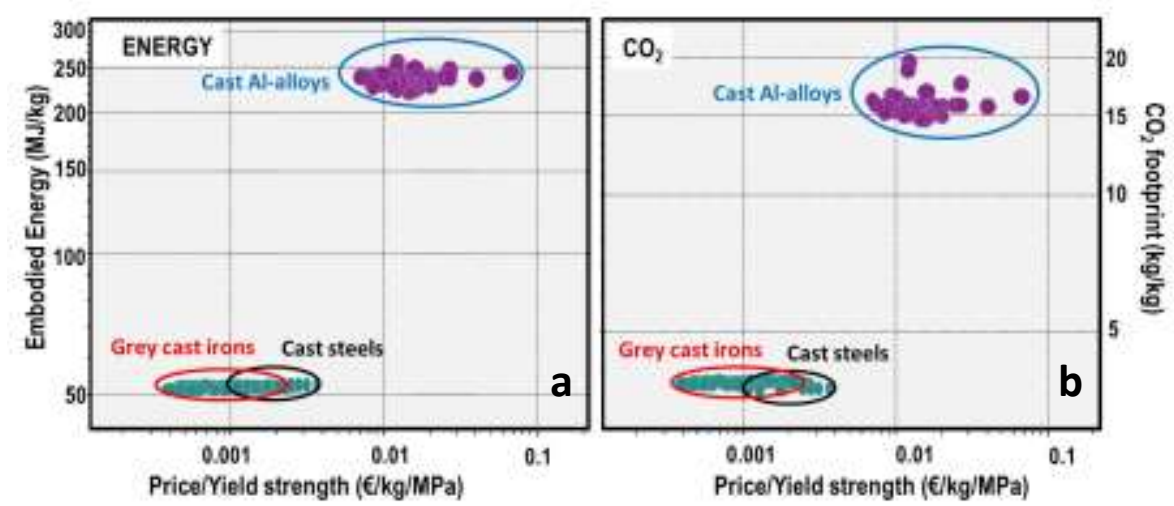

Figure 1 Gray cast iron compared with cast steel and aluminum alloy in terms of price and environmental impact. X-axes concern the ratio between price and Yield strength, while y-axes concern estimations of energy used (a) and equivalent $\mathrm{CO}_{2}$ emissions (b) for the primary production, casting and recycling of one kg of alloy. Data from Granta Edupack (2020).

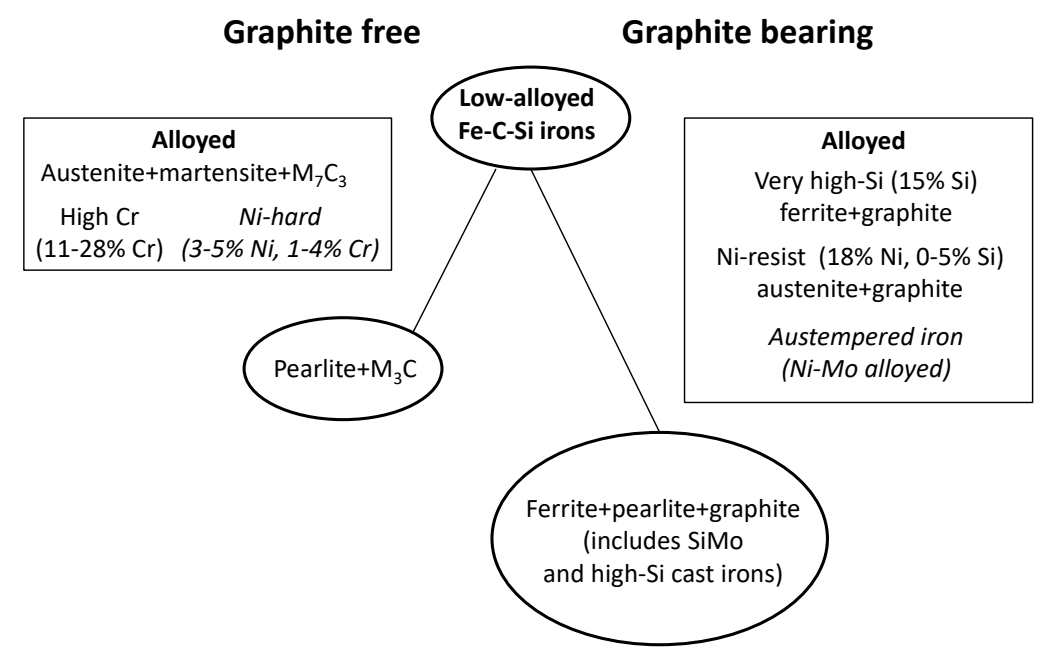

Figure 2 The cast iron family with the basic microstructures indicated. They are all obtained in the as-cast state, except those appearing in italics that are subjected to specific heat-treatment (after Elliott (1998) and Stefanescu (2018)).

The properties of silicon cast iron are determined by its microstructure after the following two transformations: (1) solidification during which the graphite shape is 
determined; and (2) solid-state transformation of the Fe-rich matrix in ferrite or pearlite. With low levels of $\mathrm{Ni}$ and Mo, silicon cast iron can be austenitized (austempered) and then transformed at $300-450^{\circ} \mathrm{C}$ to give a matrix of ausferrite. This material is called austempered ductile iron (ADI) and has very high mechanical properties. The current market share and other relevant issues are covered in more depth in a later section dedicated to production and concerns. These issues concern on-going laboratory research and are made more challenging by the increased demand for weight reduction and increased loading, coupled with an ever-increasing number of recycling loops that compound the effect of trace elements on the parameters controlling the microstructure. Some of the more recent challenges are discussed in the final section.

\section{A Very Brief History}

According to legend, "approximately 4,000 years BC, scientists and sages commissioned the first iron cupolas. These early metallurgists placed a curious metal-like substance, which we now know as iron ore, in the hollow of a burnt out tree trunk. The charred inner surface of the trunk provided fuel for the fires and thermal insulation, while random holes that burned through the trunk allowed the ambient winds to enter and feed the charcoal. With the right combination of wind, rich ores and extra charcoal, the charge was reduced to a metallic iron sponge that could be rolled, using rocks, into decorative beads. It was 6000 years ago, and iron was more highly valued than gold." (Dawson, 2001)

This quote more or less reflects what is described in historical texts, which locate the very start of the history of iron in Anatolia (Armenia) or Mesopotamia (Iran) (Stefanescu, 2018; Le Coze, 2020), or else China (Derui and Haiping, 2010). It is worth noting that a separate development in sub-Sahara Africa around the same period was postulated and is now well documented (Le Coze, 2017; Robion-Brunner, 2018). A short but comprehensive presentation of the beginnings of iron ore processing, and of the parallel development of iron and cast irons, has been published by Le Coze (2000). Production techniques and raw materials were gradually refined as the Iron Age evolved. Iron implements and weapons began to appear in approximately $3000 \mathrm{BC}$, and the comparatively advanced technique of hardening iron weapons with heat treatment was known to the Greeks by about $1000 \mathrm{BC}$.

As the temperature of the furnaces was progressively increased and reached $970^{\circ} \mathrm{C}$ (Fe-C-P eutectic), $1154^{\circ} \mathrm{C}$ (Fe-C eutectic) and above, some liquid may have formed which was certainly mixed with scoriae. Increasing the temperature further, to slightly above $1200^{\circ} \mathrm{C}$, allowed the formation of $\mathrm{FeO}$-fayalite or fayalite- $\mathrm{SiO}_{2}$ eutectic, meaning the dross and scoriae became partly liquified and could be separated more easily from the iron loupe. In most production locations, this carbon enriched liquid iron-the ancestor of cast ironwas phased out, except in China, where the first crafts, tools, and weapons made of cast iron date back to 600-500 BC (Stefanescu, 2018; Derui and Haiping, 2010). This meant that it was soon understood that the furnaces could be conducted either to produce "wrought" iron for further refining by hammering to give steel, or to make a carbon-rich iron liquid that was suitable for casting. In the latter case, adding minerals (clay, shells, ...) changed the scoriae into a slag, which protected the metallic liquid and thus maintained its casting ability while more of the charge was melting. It is probable that some silicon dissolved in the liquid, in an amount that increased with the temperature, and that it was early understood that solidification at a fast rate of cooling resulted in brittle components, while slower cooling yielded enough ductility to keep the cast parts in one piece when handling them. This historic development of cast iron in China contrasts with the fact that it only became recognized in Europe as late as the $14^{\text {th }}$ century AD.

Cast iron was such an "easy" material to process that it soon allowed gigantism. This 
applies to the use of cast iron to erect impressive sculptures such as the Cangzhou Lion in Figure 3 or the famous pagoda in the Yuquan temple. With some delay, the same happened in Europe with the $35 \mathrm{~km}$ of cast iron pipes and other components that were installed during the second part of the $17^{\text {th }}$ century to bring water to the dozens of jets in the garden of the Palace of Versailles (https://en.chateauversailles.fr/discover/estate/gardens) to satisfy the egocentrism and megalomania of one single human being.

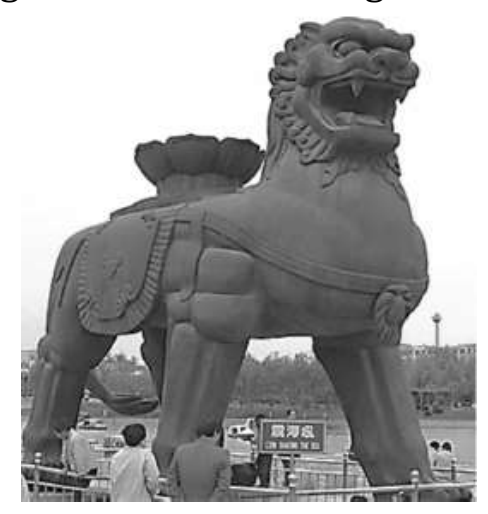

Figure 3 Iron Lion of Cangzhou, $953 \mathrm{AD}$

The development of cast iron followed the progress made in the processing of iron, which is nowadays known in detail with the evolution in Europe of the Catalan forges to larger and larger blast furnaces. Karsten described the state of the art of cast iron processing at the beginning of the $19^{\text {th }}$ century (Karsten, 1820), including a detailed description of the work by de Réaumur at the beginning of the $18^{\text {th }}$ century on the solid-state heat treatment of cast iron to give malleable cast iron and cemented iron. Two methods for making steel, i.e., the direct reduction through a pasty state that gave "wrought" iron and the remelting and oxidizing of cast iron, were used until the development of the Bessemer converter. Although metallurgy was not understood, and Bessemer wrongly concluded that air was fuel just as many before him did (Le Coze, 2017), the breakthrough was realized and steelmaking capacity could leap from kilograms per day to tons per hour. It was only with the publication of the first Fe-C phase diagram at the very end of the $19^{\text {th }}$ century that it was understood that "wrought" iron, steel and cast iron belong to the same family.

Iron ore processing required a substantial amount of charcoal so the optimization of this process became a necessity, which implied the need to increase the maximum furnace temperature. To achieve this, blast furnaces became increasingly taller with progressively better control of the air blown onto the charge. In the early $18^{\text {th }}$ century, charcoal started to be replaced with coke due to its better mechanical properties, with the notable drawback that sulfur was added to the melt. For later processing, the liquid cast iron could be tapped into a trough made in the sand floor of the foundry, where it overflowed into impressions made by the foundryman's foot on either side of the trough. Because the shape of the footsized ingots along the trough resembled piglets feeding at a sow, the small ingots became known as pig iron.

Even though, at this stage, cast iron metallurgy had not yet been perfected, casting technology was already at an advanced stage. This is illustrated with Berlin iron (fer de Berlin) jewelry that came into fashion during the early 1800s when Prussia was looking to finance its war against Napoleon. The Prussians were asked to turn in their gold jewelry to raise funds for the war and were given iron jewelry in return. Berlin iron was sand-cast and then lacquered black. Many such pieces can be found in museums in continental Europe, but also in Brazil where the fashion was exported at the same time the country built its first blast furnaces; see Figure 4. 


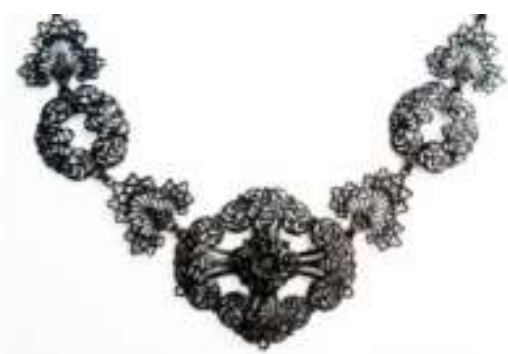

Figure 4 Brazilian cast iron necklace inspired by the fashion known as Berlin iron, early $19^{\text {th }}$ century (Santos, 2021). With permission from Irina Aragão and Anais do Museu paulista (Brazil)

Around this time, cupolas and other kinds of furnaces for melting and processing irons and steels were being developed. Present-day blast furnaces are defined as facilities that provide pig iron for immediate use, particularly in integrated steel mills. Cupolas, in contrast, were designed for manufacturing stocks of cast iron to be processed later. They evolved over time and became the most common means of melting the charge in foundries. Today, high-volume foundries use a combination of cupola and electric induction furnaces to melt the iron. The melting costs of both techniques are similar, but the cupola has an advantage in terms of productivity. Large cupola furnaces can melt more than 100 tons per hour in a single furnace while the largest induction furnaces can only produce approximately 20 tons per hour. Despite these advantages, the cupola will eventually be assigned to the history books. In Europe, the cupola will likely be phased out by 2050 as part of the Net Zero European Green Deal. This is beneficial to the environment, but potentially devastating for the European foundries who must continue to battle international competition.

\section{The Main Steps during the Modern Era (Anthropocene)}

Scientific and technical advancements are often intertwined with industrial progress, though the latter is often led by economic factors. In the case of iron and steel, this relationship was told from a historical perspective by Le Coze (2000), who stressed the significance of the technical evolution between $400 \mathrm{BC}$ and $1400 \mathrm{AD}$ in contrast to the explosive and parallel scientific and technical changes that have occurred since then (Le Coze, 2000) The advent of chemical analysis, microscopic observations, and other metallographic tools such as X-rays underpinned the improvements made in the properties of these materials.

Until the $19^{\text {th }}$ century, the composition of cast parts was given by that of the iron ore (Wittmoser, 1959) and also, though not understood at that time, by the minerals that were added to generate the slag. The importance of the slag composition for limiting iron loss (as $\mathrm{FeO}$ ), as well as the removal of sulfur from the coke and phosphorus from the ore, has grown gradually, mostly in the $20^{\text {th }}$ century. Slag is generally described by its basicity, which is the ratio of basic oxides ( $\mathrm{CaO}, \mathrm{MnO}, \mathrm{FeO}, \mathrm{Na}_{2} \mathrm{O}$ ) to acid oxides ( $\mathrm{SiO}_{2}, \mathrm{P}_{2} \mathrm{O}_{5}$ ). Nowadays, by controlling the composition of the slag and the temperature at the metal/slag interface in a blast furnace, it is possible to produce a cast iron with the desired silicon content. Beyond the cast iron industry, modern steelmakers have taken slag science to new heights, leading to the expression: "take care of the slag and the iron will take care of itself".

Until the middle of the $20^{\text {th }}$ century, the main concern was low ductility and the resulting moderate tensile strength caused by the lamellar shape of graphite, see the bottom-left micrograph in Figure 5. In the 1940s, following earlier attempts in Germany, Morrough and Williams in England and Millis and co-workers in America sought a way to 
ball graphite. The British (at BCIRA) found that the addition of less than $0.1 \%$ cerium was sufficient to cause the graphite to grow in the form of individual spheroids instead of flakes. The Americans (at Inco) found that adding approximately $0.05 \%$ magnesium gave similar results. The Inco magnesium process eventually won the battle on technical grounds, and the annual worldwide production of spheroidal graphite (aka nodular graphite or ductile) iron (SGI) has since grown to more than 25 million tons.

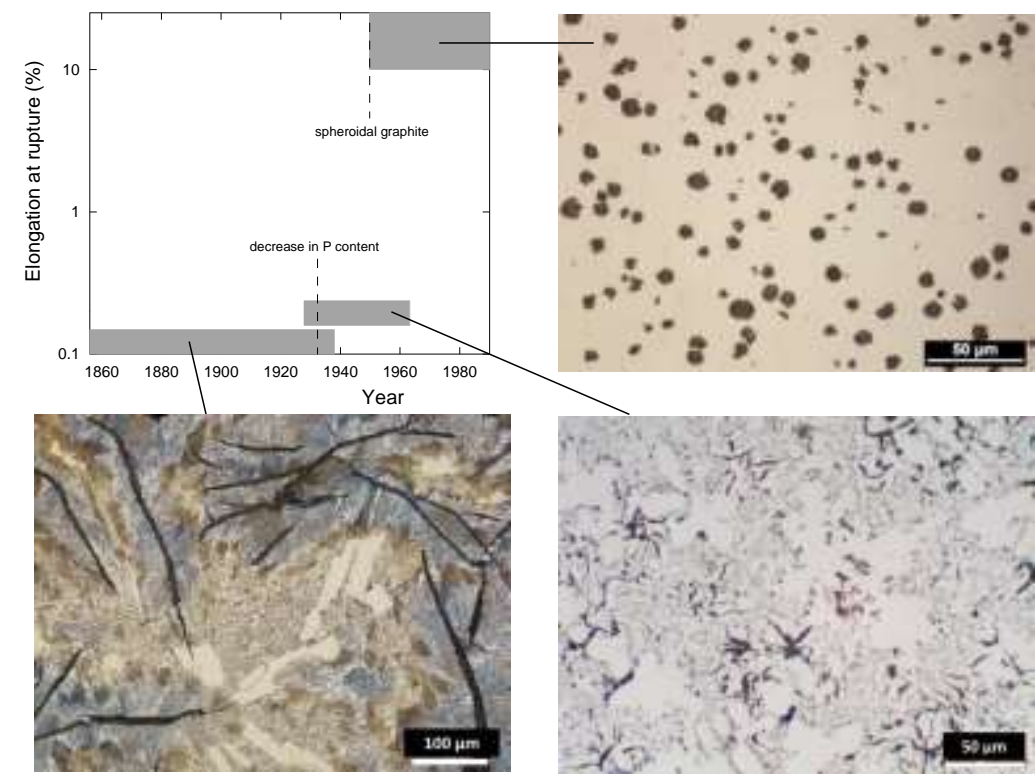

Figure 5 Evolution of the elongation at rupture of cast iron used for water pipes (adapted from Lesoult et al. (1984)) and its microstructure. Graphite appears in dark contrast in the micrographs. The samples were etched to reveal the constitution of the matrix, which was pearlite in the historical material (with some coarse eutectic cementite) and ferrite in the two centrifugally cast pipes. Note that centrifugally cast LGI and SGI are both heat treated immediately after casting for full graphitization

The modification of the graphite shape from flakes to nodules had a profound effect on the properties and the market potential of cast iron. In comparison to gray iron, the tensile strength tripled, the stiffness increased by $50 \%$ and ductility or elongation changed from close to $0 \%$ to more than $5 \%$, and up to more than $25 \%$ with a ferritic matrix. This quantum step in cast iron technology is illustrated in Figure 5, which shows the case of cast iron pipes manufactured by the Pont-à-Mousson company that was created in the mid-19 ${ }^{\text {th }}$ century. This figure presents the parallel evolution of the elongation at rupture and of the microstructure of the cast irons. The microstructure at the turn of the $20^{\text {th }}$ century was certainly similar to that of the pipes in Versailles, which is illustrated here. Brittleness of cast iron parts was an issue, not only due to the lamellar shape of graphite but also because the parts contained large precipitates of eutectic cementite and some phosphides. The treatment of the melt or the selection of iron ore allowed the phosphorus content to be halved and thus suppressed the occurrence of phosphide. Around the same period was introduced the centrifugal process in which the melt is poured into a water-cooled, rotating metallic die. This led to a significant refining of the microstructure of lamellar graphite irons (LGI), in particular by shortening the graphite lamellae. The dramatic change witnessed in the 1950s was due to the switch to SGI, instead of LGI.

Millis et al. also received a patent, in 1949, for a gray iron with improved properties resulting from graphite that had assumed a more compact shape than the usual flakes. The compact graphite shape was achieved by adding a controlled amount of magnesium and 
later became known as compacted graphite iron (CGI). Interestingly, the patent was applied for in 1948 on the same day as Millis' more famous ductile iron patent, and the two patents were granted on the same day in 1949, with US patent number US2485760 for SGI and US2485761 for CGI. CGI has superior mechanical properties to LGI and is much less prone to microporosity than SGI. Critically, for modern engine applications, CGI also has higher thermal conductivity than ductile iron. However, it was only in the 1960s that interest grew in purposely generating this intermediate graphite form (see the review by Nechtelberger et al. (1982)). CGI has thus been in use for an extended period of time; however, this was only for niche applications until the development of a proper thermal analysis control of the melt preparation immediately prior to casting. The first series production of CGI engines for passenger vehicles was launched by Audi in 1999 and, since the beginning of the 21 st century, CGI has broken into the market of automotive engines and components though not yet appearing as such in production trends that only differentiate data from LGI, SGI and malleable iron (Stefanescu, 2019).

Nowadays, graphite is industrially spheroidized by the simultaneous addition of magnesium and rare earths (RE). In contrast, there are several ways to generate compacted graphite as reviewed by Nechtelberger et al. (1982). However, the most common method is by the addition of Mg and RE in more limited amounts than in SGI. Figure 6 shows the change in graphite nodularity in relation to adjustment of $\mathrm{Mg}$ content (Microstructure and Porosity Control, SinterCast). It also illustrates the domains and typical examples of graphite shape for LGI, CGI and SGI. Note that the nodularity was set negative for lamellar graphite to emphasize that the industrial nodularity scale is defined for compacted and spheroidal graphite and not for lamellar graphite, for which letters (A-E) are used to differentiate the various shapes (Dawson, 2003). The evolution of ultimate tensile stress (UTS) with nodularity for $85-100 \%$ pearlitic cast iron is also illustrated.

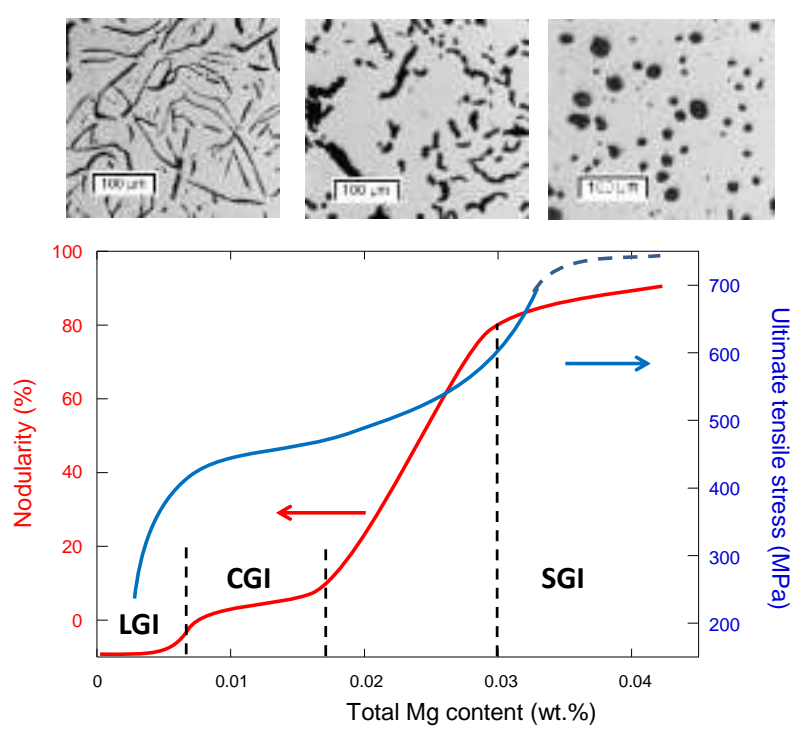

Figure 6 Evolution of graphite shape and UTS (pearlitic matrix) with Mg content, illustrated for a base iron sulfur content of $0.013 \%$ (Microstructure and Porosity Control, SinterCast)

The composition of most of the silicon cast irons is selected on the basis of the graphite shape, as illustrated in Figure 7 (adapted from Elliott (1998)). This graph shows the projection of the iron-rich corner of the Fe-C-Si diagram with the solubility limit of carbon in austenite (at eutectic temperature) that defines the lower limit of the cast irons' domain. The upper limit of carbon content is slightly higher than the eutectic line. White cast irons are low-silicon hypo-eutectic alloys and are gradually being replaced by high-Cr cast irons 
for wear property. Their use is mostly limited to the manufacture of malleable iron by heattreatment. LGI is mostly hypoeutectic, with the austenite dendrite network guaranteeing a minimum rupture elongation. If it were possible to produce LGI with higher carbon content, the industry would do this to maximize thermal conductivity. The main barrier to achieving this is the need to restrict the carbon content to ensure: (i) that the graphite does not cause brittleness; and (ii) that there is sufficient austenite to carry the load and compensate for the ill-effects of the graphite. CGI and SGI are near-eutectic alloys for minimizing microporosity.

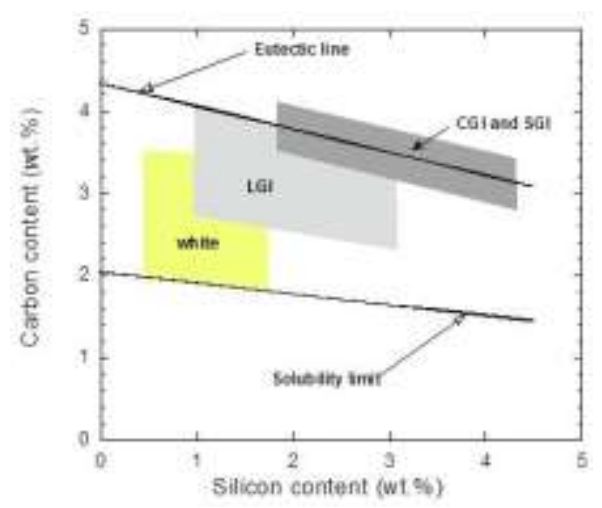

Figure 7 Carbon and silicon composition ranges of silicon cast irons (adapted from Elliott (1998))

The trend for higher silicon content in SGI and CGI started in the early 1980s with the development of the so-called SiMo cast iron for exhaust manifolds. Higher Si content raises the eutectoid temperature and thus increases the maximum service temperature. When Mo is added, it creates a network of eutectic carbides that improves creep properties. However, as exhaust temperatures continue to rise to satisfy emissions requirements, SiMo exhaust manifolds and turbocharger housings are being widely replaced by stainless steels that do not incur a phase transformation. These higher temperature capabilities outweigh the fact that oxide scales are generally better at adhering to cast iron than to steel.

Since the 2000s, high-silicon SGI has developed as the yield stress and ultimate tensile stress are linearly increasing with Si concentration because of partial ordering of the ferritic matrix. This means mechanical properties similar to pearlitic irons may be obtained, with the resulting advantage of a decrease in tool wear during machining due to having a more homogeneous matrix. More generally, there is a wealth of research for improving the mechanical property of the matrix of cast iron. Amongst the many possibilities that have been considered, austempered cast irons are slowly showing very promising industrial potential.

\section{An Overview of Current Cast Iron Production and Related Issues}

Various forms of cast iron are found in pipes, machinery, railway, automotive and energy industries, as well as in cooking and ornaments in public areas, etc. Figure 8 indicates the market share for SGI (about 25 million tons per year) and LGI (about 50 million tons per year) based on the 2018 USA data (Metalcasting Forecast and Trends, 2019), which are certainly representative of the world market. 

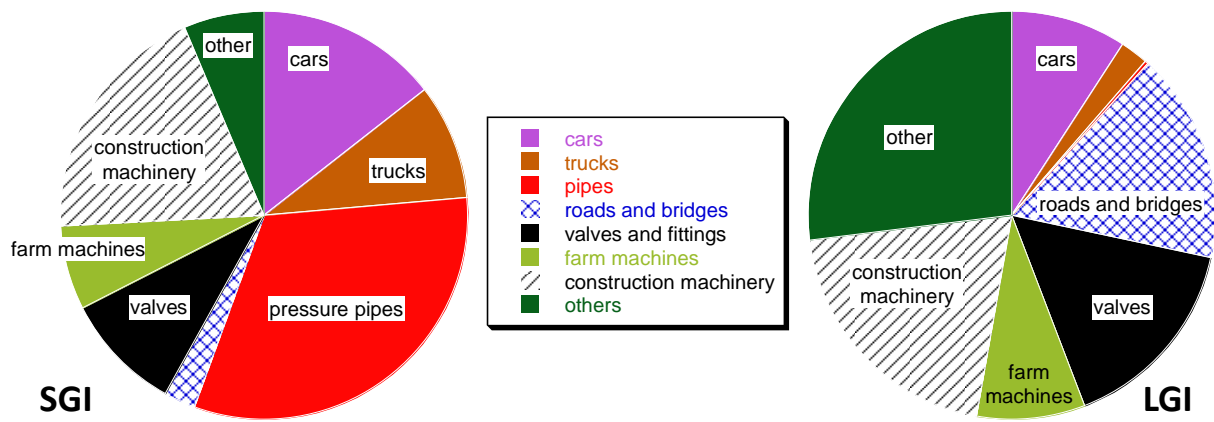

Figure 8 Market distribution in USA in 2018 for SGI (to the left) and LGI (to the right) (Metalcasting Forecast and Trends, 2019). CGI data are included in the LGI data as the primary application for CGI is cylinder blocks and heads

After the panic created by the COVID-19 pandemic, things appear to be up and running again, and following the same steps as before. In particular, there is no longer any question about the fact that the demand for the transportation of goods must be met, which has led to the development of large-scale cargo ships that require compatible engines (Figure 9). These engines are run with high-sulfur oils that create air pollutants at an incredible rate; however, significant progress is being made in this field as well. Since low-sulfur fuel was mandated in 2020, longer-stroke engines provide improved efficiency from their reduced revolutions per minute (rpm), and there is the prospect of the introduction of ammonia as an alternative fuel in the near future. Stronger cast irons are required to ensure that this demand can be satisfied with more efficient engines and with decreased pollution.

In the introduction, we briefly mentioned that cast iron is a "green" material when compared to others cast alloys (cf. Figure 1). This is certainly not the whole truth. Similar to other engineering materials, the production of cast iron has steadily increased since the $19^{\text {th }}$ century, along with the associated increase in the negative impact on the environment (pollution, energy and primary resource consumption, green-house gas-mostly $\mathrm{CO}_{2}-$ emissions, ...), which has reached an overall level that has become unacceptable. However, sustained efforts have long been made to decrease pollution from fumes emitted during melt preparation (both blast furnaces and other foundry furnaces). Because the cupola will be banned in Europe in 2050, the full circle-from only blast furnaces and cupolas to only electric-will be closed within about two centuries.

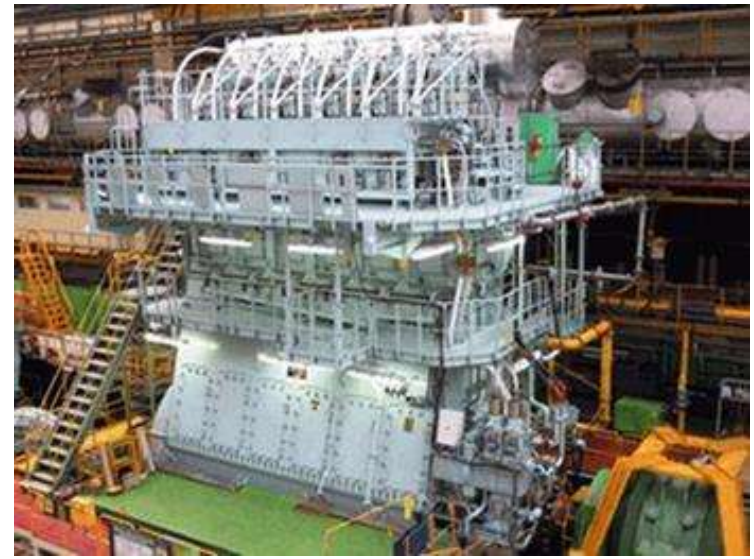

Figure 9 A large ship engine (Wärtsilä X62 engine), the steps on the left side can be used for an idea of the scale

More recently, comprehensive life cycle analyses (LCA) have been carried out, which determine the environmental impact at different steps of the whole extraction and 
production process (see, for instance, (Mitterpach et al., 2017; Jolly and Salonitis, 2017; Jhaveri et al., 2018; Salonitis et al., 2019; Stefana et al., 2019) and an example in Figure 10). This tedious work provides essential guidelines for the further reduction of energy consumption and the $\mathrm{CO}_{2}$ footprint of the casting industry. Recyclability is also one benefit of cast iron. The percentage of recycled and downcycled material in the total worldwide supply of gray cast iron has reached about $70 \%$, compared to less than $50 \%$ for cast steel or Al-alloy (Granta Edupack, 2020). Finally, a particular feature of aluminum and cast iron castings is the huge amounts of sand that is used, utilizing either green sand, which can be recycled, or sand that has been chemically bound, which cannot. It should be noted that the gravity sand casting of passenger vehicle aluminum cylinder blocks uses approximately four times more chemically bonded sand than an equivalent cast iron cylinder block.

Stronger materials, like CGI, also reduce the weight of conventional LGI components, contributing to the preservation of the environment by reducing the melting demand. If CGI reduces the weight of a gray iron cylinder block by $15 \%$, the saving corresponds to 7,500 tons per year in casting and 10,000 tons per year of liquid metal for every one million 50 $\mathrm{kg}$ cylinder blocks produced. In turn, this saving amounts to a reduction of $100 \mathrm{MJ}$ of energy for electric melting and 500 tons of $\mathrm{CO}_{2}$ per year.

In the transportation industry, the biggest drawback of cast iron is clearly its high density, which would suggest a need to substitute it with lighter materials, such as Al-alloy or even Mg alloy. However, this solution needs to be validated for each component, since the gain in energy consumed (or $\mathrm{CO}_{2}$ generated) during service cannot always counterbalance the excess use of energy for the production of the lighter alloy (cf. Figure 1 and Figure 10a). As an example, Figure 10b (from Salonitis et al. (2019)) shows that the break-even distance for paying back the substitution of cast iron with Al-alloy in any given engine block is similar to, or even exceeds, the service life of the vehicle.

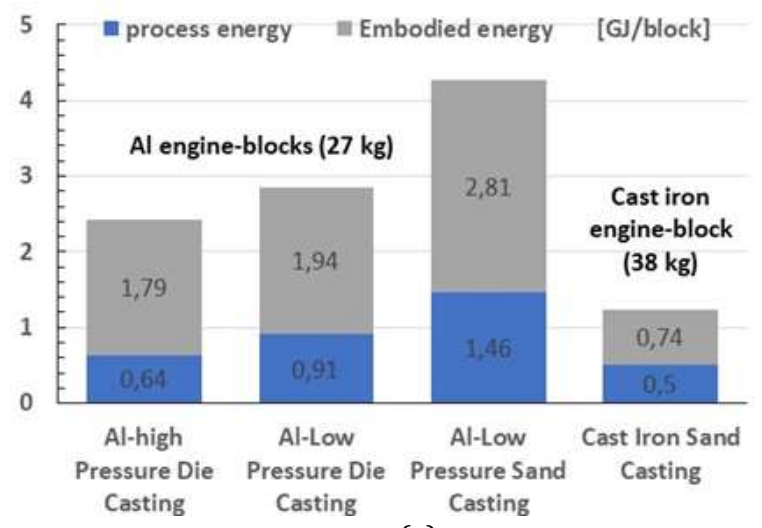

(a)

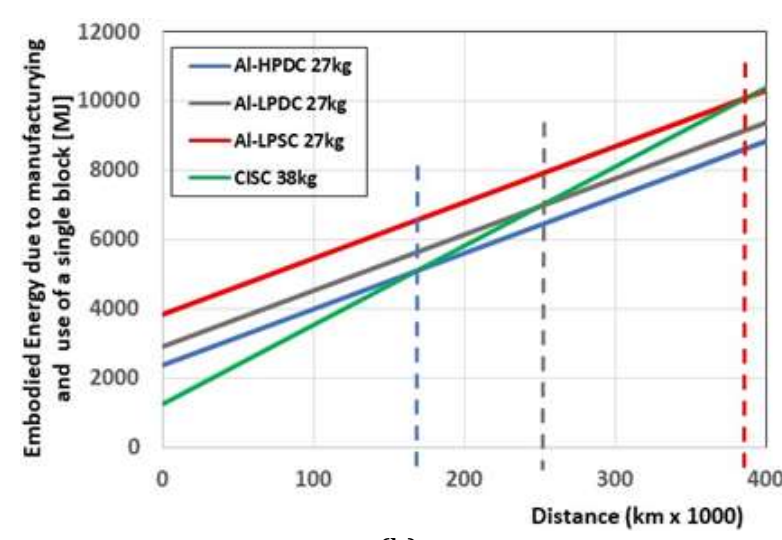

(b)

Figure 10 (a) Energy for manufacturing a $1.6 \mathrm{~L}$ diesel engine block made of cast iron (38 kg) or Al alloy (27 kg); (b) Total (manufacturing + use) energy as a function of driving distance for the same engine block in an automotive vehicle of $1200 \mathrm{~kg}$ with an average consumption of $7 \mathrm{~L} / 100 \mathrm{~km}$; vertical dotted lines mark break-even distances between cast iron and Al-alloy produced by different casting processes; the average life of such a vehicle is approximately $220000 \mathrm{~km}$. (adapted from Salonitis et al. (2019)).

While considerable attention is paid to the electrification of passenger vehicles, the market penetration to date-and the likely development over the next decade-is not as rapid as many media reports are suggesting. The pie charts on the right of Figure 11 show passenger car sales for Europe, the US and China in 2020, categorized by fuel, namely petrol, diesel, hybrid, electrified (plug-in hybrids plus battery electric vehicles) and alternative fuel 
(propane, natural gas, etc.). Globally, passenger vehicle electrification in 2020 was less than $10 \%$ and, as shown in Figure 11, global sales are expected to be approximately 30\% in 2030. Many of these vehicles will be hybrids, also containing an internal combustion engine. On the commercial vehicle side, there is no foreseeable alternative to the diesel engine for longhaul heavy-duty goods transport and there is a widespread consensus in the industry that the diesel engine will dominate until at least 2040. Even if the transformation to electrification becomes complete, the internal combustion engine will remain prevalent on roads all over the globe for decades after production stops. Clearly, there is a need for continued research into cast iron to make the internal combustion engine as environmentally effective as possible.

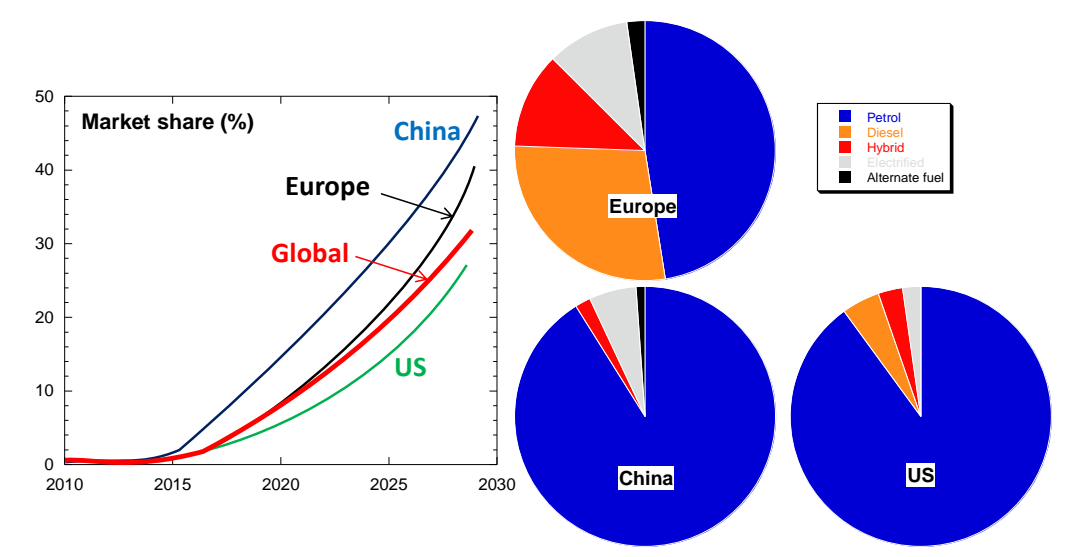

Figure 11 Penetration of electrically charged vehicles is poised to remain below $50 \%$ for at least the next decade (adapted from Automotive News, 17 May 2021). The pie charts show passenger car sales in 2020 for Europe, the US and China according to fuel

\section{Future Outlooks: A Material Worthy of Further Research}

At the end of the $20^{\text {th }}$ century, progress in metallurgy has benefited from the development of computers and small-scale analytical methods. Computer capabilities have been first utilized for developing simulation tools for describing the successive processes of melt preparation, filling and casting, and several commercial software packages are currently available. Another important application is in the control of melt preparation just before pouring. This makes use of thermal analysis with dedicated rapid curve analysis so that a green or red light is given prior to casting, enabling the foundry to adjust the iron and to ensure that only good iron is poured. However, the most exciting advance for metallurgists is the ability of modern apparatus to investigate matters on a small-scale, even going down to atom scale, as in the case of so-called Atomic Resolution Microscopes. This certainly opens the way to increasing our understanding of microstructure formation in cast iron.

To reduce overall costs, it is desirable to use cast iron parts in their as-cast state, which means avoiding heat-treatment. This implies that the graphite shape and the matrix constitution that were sought for are obtained, which may be particularly challenging when a part has a complex shape. In fact, the shape of graphite is highly sensitive to small changes in both melt preparation and cooling rate. Furthermore, changes brought about by these factors are closely inter-related; see Figure 12 . After standard preparation, a cast iron melt yields flake graphite, while a full or partial spheroidizing treatment after desulfurization is used to get spheroidal or compacted graphite, respectively. However, in a casting with sections of various thicknesses, the graphite shape depends on the local cooling rate. The following changes can be witnessed as the cooling rate increases: 
- Lamellar graphite to undercooled graphite.

- Compacted graphite with low nodularity to nearly or fully spheroidal graphite.

- Irregular spheroidal graphite to well-rounded.

Inoculation helps control graphite shape, e.g., avoiding undercooled graphite in LGI that would conduct to a ferritic matrix, while fully pearlitic LGI is preferred for its mechanical properties. Furthermore, obtaining a fully graphitic SGI upon casting definitely relies on the appropriate inoculation of the melt for preventing the formation of metastable eutectic. Understanding the bases of the formation of graphite nuclei (Skaland et al., 1993; Loper, 1998) has allowed to define new inoculant compositions, which are particularly useful in combating fading and porosity in SGI. This is an area of fierce competition from an industrial point of view and also stimulates the interest of scientists. The main concern is understanding early precipitation and growth of graphite, in particular in relation to the presence of additives in the inoculants. Recent results on hypereutectic alloys strongly suggest that both primary and eutectic growth of graphite need significant undercooling to proceed, and that this undercooling depends on melt chemistry (Castro-Roman, et al., 2020). This should lead to a revisiting of thermal analysis records as well as the modelling approaches of cast iron solidification.

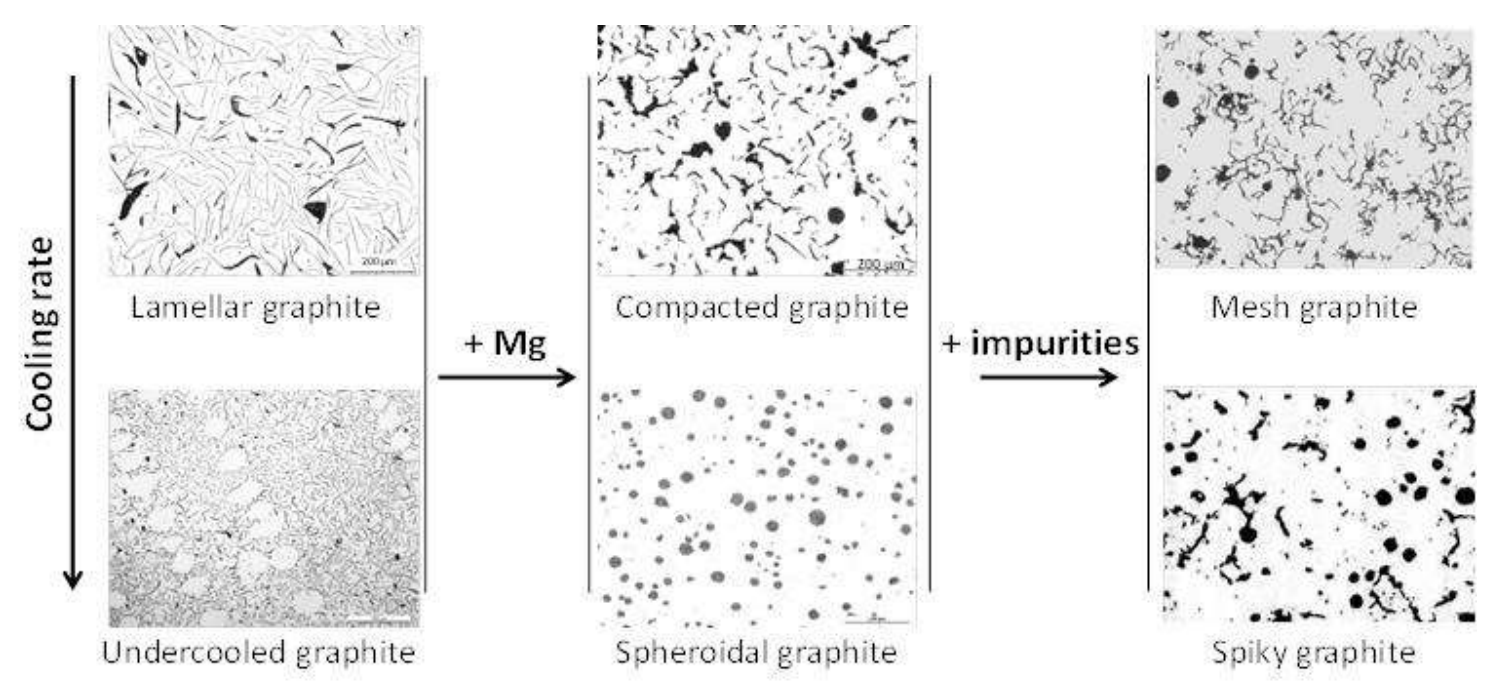

Figure 12 The interplay between chemical and cooling rate routes (after Lacaze et al., 2020)

The additives mentioned above are elements prone to reacting with oxygen, sulfur, and nitrogen to precipitate compounds that are active in the process of graphite nuclei formation. However, at the same time, many of these elements also affect graphite shape and are then seen as impurities leading to graphite "degeneracy" - i.e., the development of unwanted graphite forms - when present in the melt at, or above, a critical level that may be so low that these so-called poisoning elements can often be classified as trace elements. These degeneracies are illustrated in Figure 12 with mesh and spiky graphite in the case of SGI, but the phenomenon is also known to occur in LGI and CGI. While the role of these impurities has been recorded for a long time, as can be seen in several reviews (Sawyer et al., 1968; Javaid and Loper, 1995), comprehending the role they play in inducing graphite degeneracy is still in its infancy (Lacaze and Dezellus, 2021). In practice, rare earth (RE) is used to fight the deleterious effects of trace elements. Again, there has been scant description of the kinetics of the variety of precipitation and dissolution processes behind rare earth additions (Lekakh, 1998; Lekakh et al., 2009). 
The precise mechanism behind the action of spheroidizers is still unknown, or more precisely, still controversial. The primary effect of magnesium and rare earth has long been associated with their high affinity with oxygen and sulfur, i.e., the thinking that change in graphite shape is controlled by tightening oxygen and sulfur as oxysulphides. Subramanian et al. (1982) therefore suggested associating the different forms of graphite with the thermodynamic activity of residual oxygen and sulfur. The presence of some residual magnesium and RE dissolved in the liquid of a melt dedicated to SGI and CGI appears, however, essential for achieving the desired graphite shape. The challenge of understanding the exact way in which these elements interact with graphite still remains.

Similar to graphite shape, the constitution of the matrix in the as-cast state depends both on the chemical composition and on the cooling rate, with graphite fineness also a significant factor. Increased inoculation in SGI and decrease in graphite size in LGI eases the transformation of the matrix in the stable system, i.e., increases the amount of ferrite. On the other hand, increased cooling rate favors the transformation in the metastable system with precipitation of pearlite. Sn and $\mathrm{Sb}$ are utilized industrially to prevent the formation of ferrite, with the risk of graphite degeneracy if over-added. It is therefore usual to also add $\mathrm{Mn}$ and $\mathrm{Cu}$, which are less potent for pearlite formation but are also easier to tolerate when considering how to avoid the formation of deleterious graphite shapes. An important feature of the eutectoid transformation is microsegregation that develops during solidification. While microsegregation is relatively easy to describe (Eiken et al., 2020), mastering it is key for controlling the eutectoid transformation and has yet to be successfully achieved. Microsegregation is also an issue for the austempering of ADI parts as well as for so-called dual-phase microstructures. It is worth noting that recent studies have demonstrated that 1-3 wt.\% Al added to a silicon cast iron inverses silicon segregation (Muhmond and Fredriksson, 2015; Franzen et al., 2019). This finding may soon be exploited to decrease microsegregation and thus improve the matrix properties of cast iron.

Improvements in melt and casting processes, as well as advances in our understanding of microstructure formation, are triggered by the need for better service within the framework of competition between materials. For dynamic properties, in particular in the case of SGI, it is not only the matrix constitution that is important but also casting defects such as porosity. Some progress has been made in describing porosity formation (Kweon et al., 2020), though the mechanical effect due to graphite bulging has long been recognized but has rarely been effectively analyzed (Lesoult, 2009). Also, the mechanical behavior of cast iron is intrinsically elasto-visco-plastic with a significant contribution of damage. This has led to a wealth of complex modelling approaches, which are difficult to introduce in foundry software packages. Ad hoc models fitted to experimental mechanical behavior are often preferred.

Beyond metallurgy itself, significant improvements continue to be introduced to the mechanical engineering side of the foundry. Over the last 25 years, complex components, like cylinder blocks and heads, have progressively evolved from green-sand casting to fully enclosed core packages. Parallel to this, minimum wall thickness for passenger vehicle cylinder blocks has decreased from $4.5 \mathrm{~mm}( \pm 1.0 \mathrm{~mm})$ to the current state-of-the-art 2.7 $\mathrm{mm}( \pm 0.5 \mathrm{~mm})$. And this development has not stopped. Until recently, 3D sand printing was maintained for rapid prototyping, but many series production foundries are now embracing additive manufacturing for the production of highly complex cores. Without draft angles, these complex cores can add to weight reduction and eliminate costly-and energy consuming-post processing of castings. 


\section{Conclusions}

We continue to judge the iron foundry by its grey walls, despite the significant progress in cleaning up the dust. The real image should be the atoms, not the walls. Cast iron is the first composite material, and it remains one of the most versatile composites available today from a technical point of view, and one of the most fascinating from a scientific point of view. In the future, iron foundries will produce castings with different graphite shapes in different areas of the component to optimize specific properties where they are needed. While the iron foundry world may struggle for image, our present-day ability to control alloy additions to within 10 grams per ton will soon seem rudimentary. The real iron-age is just beginning and the next iron will build its own legend.

\section{Acknowledgements}

F. Landgraf, Uni. Sao Paulo, and W. Menk kindly provided historical references.

\section{References}

Castro-Roman, M.J., Lacaze, J., Regordosa, A., Sertucha, J., del Campo-Castro, R., 2020. Revisiting Thermal Analysis of Hypereutectic Spheroidal Graphite Cast Irons. Metallurgical and Materials Transactions A, Volume 51(12), pp. 6373-6386

Census of Word Casting Production, 2019. Modern Casting. pp. 22-25

Dawson, S., 2001. A Brief History of ... Foundry, Engine Technology

Dawson, S., 2003. Cast Iron Alloy and Method Making the Same, US Patent 6,613,274 B2

Derui, T., Haiping, L., 2010. An Illustrated History of Ancient Chinese Casting. In:

Organization Committee of the 69th World Foundry Congress, pp. 54-65

Eiken, J., Subasic, E., Lacaze, J., 2020. 3D Phase-Field Computations of Microsegregation in Nodular Cast Iron Compared to Experimental Data and CalPhad-based ScheilPrediction. Materialia, Volume 9, https://doi.org/10.1016/j.mtla.2019.100538

Elliott, R., 1998. Cast Iron Technology. Butterworths, London, pp. 1-45

Franzen, D., Weiss, P., Pustal, B., Bührig-Polaczek, A., 2019. Influence of Aluminium on Silicon Microsegregation in Solution Strengthened Ductile Iron. Materials Science and Technology, Volume 35(6), pp. 687-694

Granta Edupack, 2020. Ansys/Granta Inc. Available Online at https://www.grantadesign.com/news_articles/introducing-granta-edupack-2020refreshing-materials-education/

Javaid, A., Loper, C.R., 1995. Quality Control of Heavy-Section Ductile Cast Irons. AFS Trans, Volume 103, pp. 119-134

Jhaveri, K., Lewis, G.M., Sullivan, J.L., Keoleian, G.A., 2018. Life Cycle Assessment of ThinWall Ductile Cast Iron for Automotive Lightweighting Applications. Sustainable Materials and Technologies, Volume 15, pp. 1-8

Jolly, M.R., Salonitis, K., 2017. Primary Manufacturing, Engine Production and on-the-road $\mathrm{CO}_{2}$ : How can the Automotive Industry Best Contribute to Environmental Sustainability? In: Vienna motor symposium

Karsten, C.J.B., 1820, French translation by F.J. Culmann, 1820: Manuel de la métallurgie du fer, tome 2, Available Online at https://gallica.bnf.fr/ark:/12148/bpt6k98189063/f142.image.r=silice

Kweon, E.S., Roh, D.H., Kim, S.B., Stefanescu, D.M., 2020. Computational Modelling of Shrinkage Porosity Formation in Spheroidal Graphite Iron: A Proof of Concept and Experimental Validation. International Journal of Metalcasting, Volume 14, pp. 601-609 
Lacaze, J., Dezellus, 0., 2021. Surface Tension, Interfacial Segregation and Graphite Shape in Cast Irons. Metallurgical and Materials Transactions $B$, Available Online at https://doi.org/10.1007/s11663-021-02352-x

Lacaze, J., Sertucha J., Castro-Roman, M.J., 2020. From Atom Scale to Casting: A Contemporary Monograph on Cast Irons Microstructure. Unspecified, Available Online at https://oatao.univ-toulouse.fr/26869/

Le Coze, J., 2000. Purification of Iron and Steels, A Continuous Effort from 2000 BC to AD 2000. Materials Transactions JIM, Volume 41, pp. 219-232

Le Coze, J., 2017. Récits sidérurgiques d'hier et d'aujourd'hui. Fers, Fontes, Aciers: 4000 ans d'affinage et de purification. EDP Sciences

Lekakh, S., 1998. Effect of Non-metallic Inclusions on Solidification of Inoculated Spheroidal Graphite Iron. International Journal of Metalcasting, Volume 13(2), pp. 129-138

Lekakh, S., Richards, V., Peaslee, K., 2009. Thermo-Chemistry of Non-Metallic Inclusions in Ductile Iron. International Journal of Metalcasting, Volume 3(4), pp. 25-37

Lesoult, G., 2009. Microporosity in Cast Alloys: Simple Considerations on its Formation. International Journal of Cast Metals Research, Volume 22, pp. 1-4

Lesoult, G., Bellocci, R., Grandpierre, M., 1984. Les fontes à Pont-à-Mousson, CR PAM (Pontà-Mousson)

Loper, C.R., 1998. Inoculation of Cast Iron-Summary of Current Understanding. AFS Trans. Volume 106, pp. 523-528

Metalcasting Forecast and Trends, 2019. AFS, Schaumburg

Mitterpach, J., Hroncov, E., Ladomerský, J., Balco, K., 2017. Environmental Evaluation of Grey Cast Iron Via Life Cycle Assessment, Journal of Cleaner Production, Volume 148, https://doi.org/10.1016/j.jclepro.2017.02.023

Muhmond, H.M., Fredriksson, H., 2015. Graphite Growth Morphologies in High Al Cast Iron. In: Advances in the Science and Engineering of Casting Solidification, pp. 323-330

Nechtelberger, E., Puhr, H., von Nesselrode, J.B., Nakayasu, A., 1982. Cast Iron with Vermicular Graphite - State of the Art. Development, Production, Properties, Applications, International Foundry Congress, CIATF, Volume 49(1), pp. 1-39

Robion-Brunner, C., 2018. L'Afrique des métaux, in L'Afrique ancienne, de l'Acacus au Zimbabwe, 20000 avant notre ère - XVIIème siècle, edited by F.X. Fauvelle (Belin, Paris, 2018), pp. 519-543

Salonitis, K., Jolly, M., Pagone, E., Papanikolaou, M., 2019. Life-Cycle and Energy Assessment of Automotive Component Manufacturing: The Dilemma Between Aluminum and Cast Iron. Energies, Volume 12(13), pp. 2557-2580

Santos, I.A.D., 2021. Rendas de ferro: uma doação pela memória civilizatória brasileira (Iron lace: a donation by the Brazilian Civilizing Memory). In: Proceedings of the São Paulo Museum: History and Material Culture, Volume 29, pp. 1-26

Sawyer, J.C., Wallace, J.F., Hallerberg, W.L., 1968. Effects and Neutralization of Trace Elements in Gray, Ductile and Malleable Iron. AFS Trans. Volume 76(part 1: 2-20 and part 2), pp. 21-32

Skaland, T., Grong, Ø., Grong, T., 1993. A Model for the Graphite Formation. Metallurgical and Materials Transactions A, Volume 24, pp. 2321-2345

Sintercast. Microstructure and Porosity Control, SinterCast Technical Description, https://www.sintercast.com/library/technical-papers-english/

Stefana, E., Cocca, P., Marciano, F., Rossi, D., Tomasoni, G., 2019. A Review of Energy and Environmental Management Practices in Cast Iron Foundries to Increase Sustainability. Sustainability, Volume 11(24), pp. 7245-7263 
Stefanescu, D.M., 2018. A History of Cast Iron. ASM Handbook, Volume 1A, Cast Iron Science Technology, ASM International, pp. 3-11

Stefanescu, D.M., 2019. The Meritocratic Ascendance of Cast Iron: From Magic to Virtual Cast Iron, International Journal of Metalcastin, Volume 13, pp. 726-752

Subramanian, S.V., Kay, D.A.R., Purdy, G.R., 1982. Compacted Graphite Morphology Control, American Foundrymen's Society, Volume 90, pp. 582-603

Wittmoser, A., 1959. Ein halbes Jahrhundert Giessereitechnik in Deutschland. Giesserei, Volume 22, pp. 630-639 